\title{
INVESTIGATION OF AVIONIC EVENTS WITH USE OF INFORMATION FROM ON-BOARD RECORDERS OF FLIGHT PARAMETERS
}

\author{
Mirosław Jemielniak \\ 3rd Airlift Wing \\ Witkowska Street 8, 62-430 Powidz, Poland \\ tel.: +4863 2774653, fax: +48632774649 \\ e-mail:mjemielniak@o2.pl \\ Mirosław Kowalski \\ Air Force Institute of Technology \\ Księcia Bolestawa Street 6, 01-494 Warsaw, Poland \\ tel.: +4822 6851101, fax: +48228364471 \\ e-mail: miroslaw.kowalski@itwl.pl
}

\begin{abstract}
The paper discloses opportunities of how information recorded by on-board recorders of flight parameters can be used for investigation of avionic events. An example of the methodical approach is presented of how to verify data acquired from flight recorders, which unambiguously indicates the feasibility of further investigation and analyses of avionic events that may happen to aircrafts.

Subsequently the effect of the engine stall is outlined, which enables analysis of those avionic events when the effect of engine(s) stall took place. The paper discloses two cases of avionic events when engine stall was the underlying reason of problems, i.e. when a helicopter entered a stream of exhaust gases produced by a missile launched by that helicopter and when icing of the intake channel occurred in a turbojet engine installed on a helicopter. Investigations of that type are indispensable due to operation constraints and technical conditions of aircrafts operations, where meeting these conditions is the principal requirements in terms of flight safety. This study confirms that opportunities to use data from on-board recorders of flight parameters to find out what was going on with the aircrafts during avionic events are considerable.
\end{abstract}

Keywords: investigation of avionic events, diagnostics of avionic driving systems

\section{Introduction}

In modern times, operation of aircrafts must guarantee, as the first and foremost prerequisite, a high level of reliability of equipment and safety of flights. It is why reliability of single units, for instance turbine avionic engines, gains more and more importance. An innovative approach to diagnostics and monitoring of avionic driving units consists in benefiting from information stored in memory of on-board recorders of flight parameters.

A recorder is a device that is installed in aircrafts to acquire key parameters of aircraft operation with attention to its drive, since the collected information can be useful to find out reasons of avionic catastrophes. Such devices are able to withstand pressure up to 5 tons and are provided with an automatic transmitter to enable location of them underwater since the transmitter broadcasts a RF signal during the time even up to 60 days (Fig. 1) [2].

Typical design of a flight parameter recorder comprises the following components (Fig. 1):

- rigid enclosure made of high quality steel or titanium,

- thermal insulation that protects the main memory unit of the recorder (usually a thin paraffin plate to absorb heat and/or thermal resistant foam capable of withstanding temperature up to $1100^{\circ} \mathrm{C}$ ), 
- information carrier - a magnetic table or an electronic memory to store the recorded data,

- underwater localizer is activated automatically when the recorder comes into contact with water (broadcasts an RF signal).

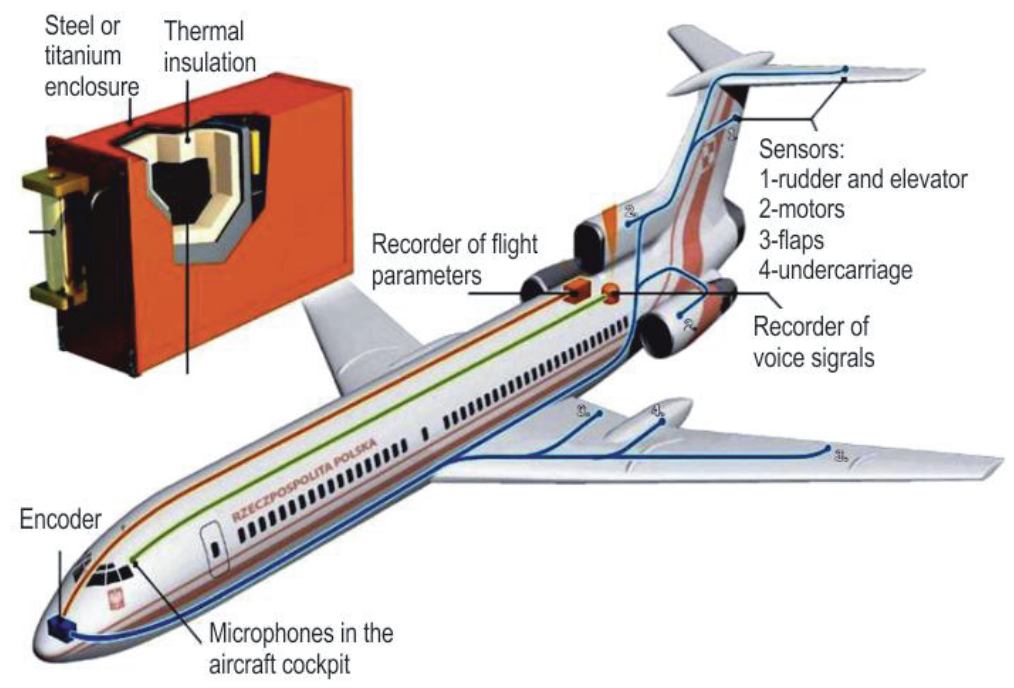

Fig. 1. Typical layout of recorders in passenger aircrafts on the example of Tu-154 airplane

Modern recorders are able to pick up as many as 400 parameters during about $25 \mathrm{~h}$. Thus, possibility to construe data from the recorders are really abundant and depend on the number of parameters recorded, technical condition of the carrier and software that is available for analysis of recorded data. Information that is stored in the device memory and their mutual correlations serve merely as one of many information sources that are used to draw up history of an avionic event.

Equipment for reading and analysis of flight parameters has been being developed independently on the recording techniques. As far as the readability of information depends on recording technique, the technical means that aid interpretation of information depend on available technologies of data processing. Initially processing of recorded information assumed mirroring of data onto a paper tape and then plots and summarizing breakdowns for individual parameters were drawn up. The analysis assumed manual comparison of available information in order to confirm or reject optional scenarios of certain avionic event. Nowadays it is possible to employ the most modern computer techniques and the investigation of data from on-board recorders of flight parameters is much more efficient and enables pretty detailed and premature identification of really hazardous avionic events but with hard identifiable symptoms.

\section{Verification of information from on-board recorders of flight parameters}

To acquire information about technical condition of objects subjected to analysis it is extremely important to collect reliable data from measurements, with appropriate structure and satisfying quality. Such information represents the base of knowledge that is necessary to learn the reality, which is achieved either by so-called logical inferring or by acquisition of quantified information expressed by numbers [1]. The basic source of information is usually an experiment that provides quantitative signals corresponding to characteristics of the object or phenomenon under investigation. Information that is stored in recorders of flight parameters can be considered as experimental data and their quality determines availability of actual information about status of the object. There are many methods suitable to record flight parameters and quality of acquired data depends chiefly on sensors and gauges. The acquired measurement signals are altered by various interferences that lead to discontinuities of data recording or distortion of basic parameters of the engine operation. Therefore, it is first necessary to carry out verification and validation of collected 
signals to find out how well they reflect the realm. For that purpose, initial tests are required to establish trustworthiness of measurements for individual parameters of the driving system operation. It is the matter of crucial importance since each parameter is sampled and recorded with various frequencies; various accuracy of recording and with use of various instruments (sensors). It is particularly important for measuring system with inherent significant deviations, like thermocouples where signals from their outputs are averaged before storage at flight parameters recorders.

The method for confidence estimation of recorded characteristics consists in execution of statistics analyses that are well known from the literature, which refers to measurements of physical parameters, as well as in comparison of analytic (expected) results against the actual (measured) data. The paper uses information stored in a recorder of flight parameters installed on board of the MiG-29 aircraft with the driving system provided with a bypass turbojet engine with twin compressor rotors of the RD-33 type. Fig. 2 and Fig. 3 show example graphs for rpm of the engine fan and compressor. These graphs were plotted on the basis of data stored in the recorder of flight parameters and considered as source information for further analyses. The recorded data sequence covers the full cycle of the engine test and comprises different phases of the engine operation. The statistical analysis was carried out for the indicated areas marked out as A1, A2, B1 and B2. These areas reveal distortions in measured rpm for already preset ranges of the engine operation. Due to the observed distortion, the measurement results were subjected to verification with use of mathematical tools for statistics analysis. The method for data verification is also suitable for application to other parameters of the engine operation recorded by the aircraft 'black box', such as temperature, torque, etc.

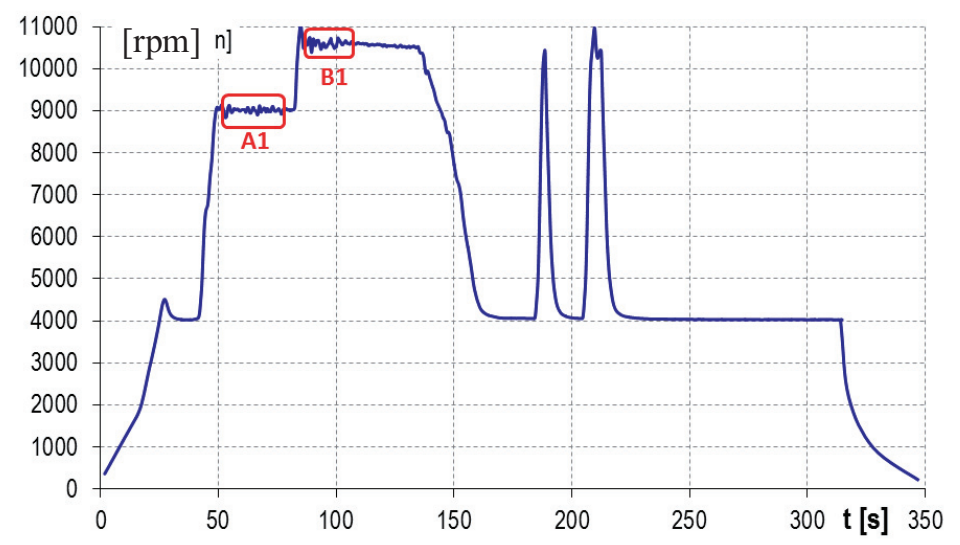

Fig. 2. Full operation cycle for the ground test of a bypass turbojet engine with twin compressor rotors of the RD-33 type (fan rpm $n_{1}$ )

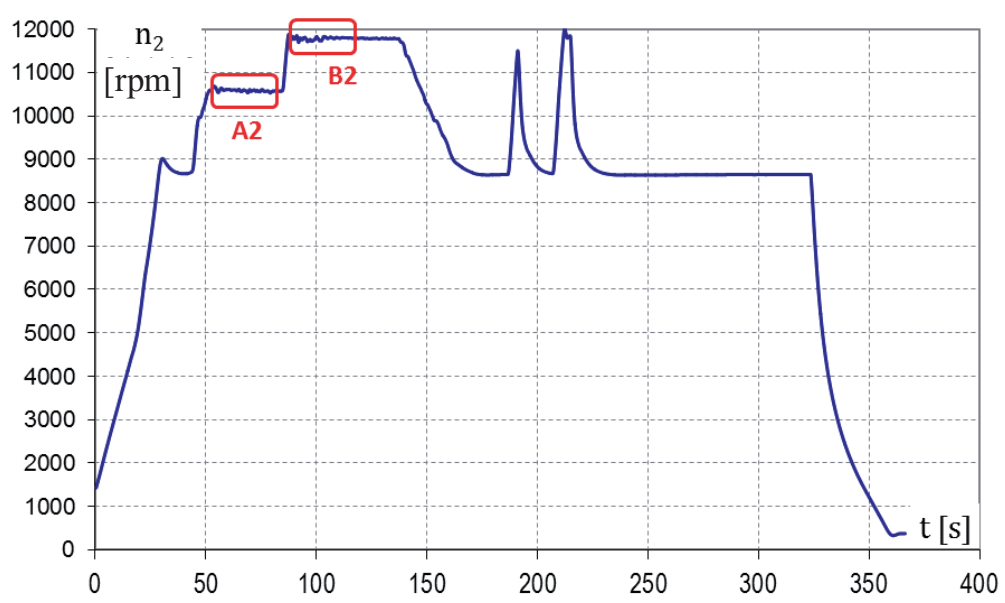

Fig. 3. Full operation cycle for the ground test of a bypass turbojet engine with twin compressor rotors of the RD-33 type (turbocompressor rpm n2) 
Number of recorded measurements (sample size) for the completed tests exceeded 3000 $(n>3000)$, which serves as the reason to assume the Gaussian distribution [1]:

where:

$$
\mathrm{N}, \frac{\sigma}{\overline{\mathrm{n}}},
$$

$\mathrm{m}$ - mathematical expectation,

$\sigma$-standard deviation for the population (for that case this parameter is unknown, therefore the standard deviation $\mathrm{S}$ for the completed test should be adopted),

$\mathrm{N}$ - sample size.

The finding of that type is very important from the point of statistics since the Gaussian distribution is the primary theoretical distribution of random variables and is used for brief description of the most frequent random processes in real world with the results very close to the average values.

The statistical analysis usually sets off from presentation of key quantitative characteristics, i.e. the figures that characterize distribution of a specific feature within the population. These are parameters for distribution of a measurement (random) variable when the same probability of occurrence equals to $1 / \mathrm{n}$ is assigned to each statistic value. It means that subsequent measurement data stored in the recorder of flight parameters can be achieved with the same probability.

According to the theory of random variables, for each measured feature $\mathrm{X}$ the following quantitative parameters can be assigned [1]:

- location (arithmetic mean, median, modal value),

- distribution (variance, standard deviation, coefficient of variation, average deviation, range),

- asymmetry (asymmetry coefficient /skewness, asymmetry index),

- flattening (kurtosis).

However, the basic tool for verification of data from measurements is so called verification of parameterized hypothesis that consists in verification of how much reliable are the information stored in the recording device for parameters of the driving unit. For that purposes the verification is carried out for so-called zero-level hypothesis that assumes that the average value of the measured parameter (with a very high probability, very near to one) is equal to the mathematical expectation $m_{0}$. The mathematical expectation is the preset parameter that is tuned up e.g. by the aircraft pilot from his cockpit according to indication of a tachometer. A hypothesis that is formulated in the foregoing manner is a statistical hypothesis and can be then verified with use of typical methods applicable to verify and validate correctness of statistical hypotheses. Each statistical hypothesis is an expectation with regard to unknown distribution of an investigated characteristic. Here the point is about the measured values of rotation speed that are parameters of the engine operation, thus such a hypothesis is referred to as a parametrical hypothesis.

To carry out verification of a hypothesis the researchers apply tests of various types. The investigation of this project the hypotheses are verified by means of the Student distribution with $n-1$ degrees of freedom.

To achieve complete and trustworthy verification, an alternative hypothesis has also been formulated that assumes that the average value of the measured parameter is so much different from the mathematical expectation that results of measurements cannot be construed as trustworthy ones.

Since the standard deviation of rotation speed is not known for the whole population of engines, it is necessary to verify the zero-level hypothesis on the basis the standard deviation $S$ determined for the completed test. In parallel, the value of so-called hypothesis test $U_{n}$ must be calculated from the relationship [1]:

$$
\mathrm{U}_{\mathrm{n}}=\frac{\mathrm{X}-\mathrm{m}_{0}}{\frac{\mathrm{s}}{\mathrm{n}-1}}
$$


For the presented example, the following values of the $U_{n}$ test were obtained:

\begin{tabular}{|c|c|c|c|c|}
\hline Area & A1 & A2 & B1 & B2 \\
\hline Hypothesis $U_{\mathrm{n}}$ & -0.03 & 0.07 & 0.05 & -0.08 \\
\hline
\end{tabular}

To accept the zero-level hypothesis as a trustworthy one the calculated value of the $U_{n}$ test should fall outside the boundaries of the so-called critical set $K$ :

$$
\mathrm{K}=-\infty ;-\mathrm{k} \cup \mathrm{k} ; \infty \text {. }
$$

The set boundaries (the number of $k$ ) are determined from the Student distribution upon assumption of certain values for the significance level of $\alpha$. Since the number of tests was $\mathrm{n}>3000$ the value of $k=2.576$ can be obtained for the Student distribution with the significance level of $\alpha=0.01$. Hence, the critical set has adopted the following form:

$$
\mathrm{K}=-\infty ;-2,576 \cup 2,576 ; \infty \text {. }
$$

Comparison between the obtained values for the test Un made it possible to find out that these values fall outside the obtained critical set. It means that the zero-level hypothesis is correct and the obtained values for the fan and the compressor of the RD-33 engine are trustworthy within the analysed areas and conform to the actual values at the level of 0.99 . The methodical approach of that type can be applied to verification of all measurement data stored in on-board recorders of flight parameters.

\section{Analysis of avionic events}

\subsection{Unsteady operation of engines - theoretical background}

Development of avionic technologies has led, in particular, to tremendous progress in design of jet engines. As the time went by the designer began to employ axial compressors that made it possible to reach high compression coefficients for air streams supplied to the combustion chamber. At the same time, the design of engines became more compact and their unit weight, i.e. the weight per power unit was reduced. Such compressors demonstrate a lot of advantages but also some essential drawbacks. The most important deficiency is high vulnerability to disturbances of inlet air stream and tendency to unsteady operation of engines (referred to as the compressor stall).

To explain the stall effect it is necessary to focus attention onto a single stage of the engine compressor for undisturbed flow of air stream (Fig. 4). During flights down a straight line or operation of the engine on the ground, the direction of air inflow (its vector) is nearly parallel to the chord of turbine blades. It is so called designed flow of air stream [3], [6], [4], [5] that is typical for undisturbed operation the compressor and assumed for calculations when no portion of air stream is detached from blade planes. In other cases, e.g. when the direction of air inflow is not parallel to blade chords the air stream is deflected towards negative angles of inflow (outwards the concave plane of blades) or positive angles (outwards the convex side of blades the tail). In such a case a disturbance a disturbance in the flow of air stream, takes place (Fig. 5 and 6). When the inflow angle is negative, (less than the design one) the delivery of air supplied by the compressor exceeds the design rating whilst at the positive angle - the air delivery is less than for typical conditions.

Such disturbances of airflow may propagate to subsequent stages of the compressor. They do not affect the entire height of blades but are usually limited to a portion of them that is shown in simplification in Fig. 7. 


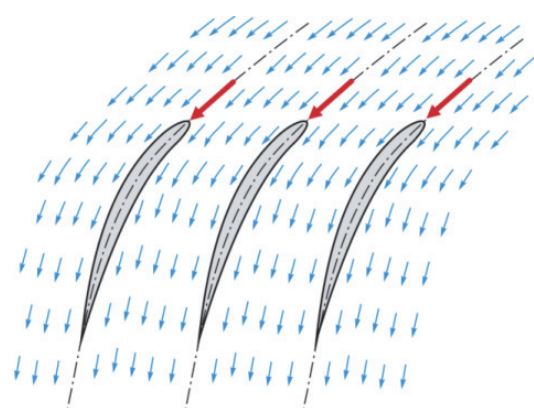

Fig. 4. Design inflow of air stream Fig. 5 onto blades of the compressor rotor

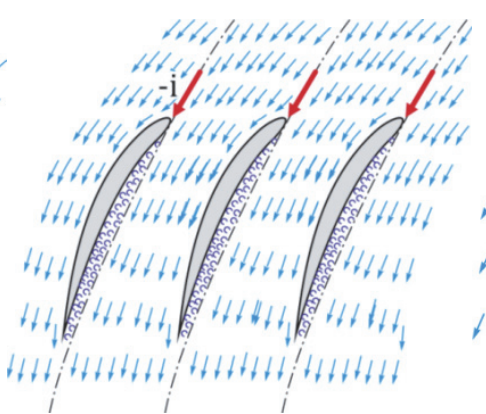

Negative angle of supplied to blades of the compressor rotor

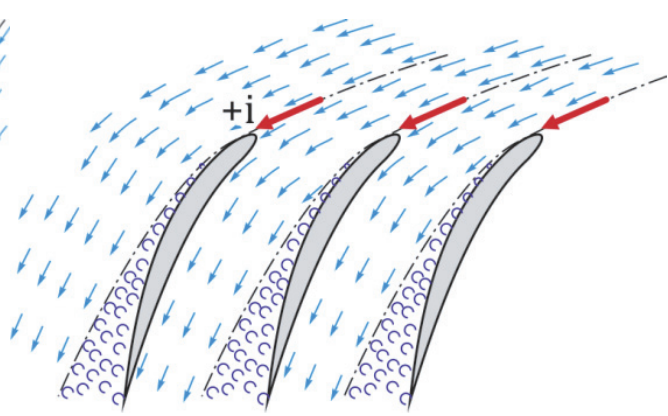

Positive angle of air flow supplied to blades of the compressor rotor

It is the phenomenon that it is very dangerous since it leads to the effect of turbine stall (unsteady operation of a turbine) that is manifested by "ejections" of air stream that is only partly compressed and is forced towards the compressor output. In case of very "deep" stalls, it is even possible to see flames that appear at the end of the engine inlet that is a symptom of very violent degree of the phenomenon, which is strong enough to drag flames from the combustion chamber towards the engine intake.

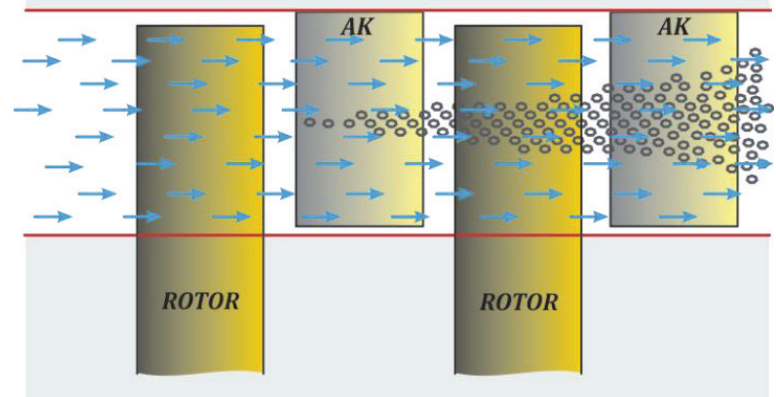

Fig. 7. Propagation of disturbances in flow of air stream to subsequent stages of a compressor

Is if why one has to remember that excessively violent movements of the engine control lever (DSS), in particular during the engine acceleration (excessively fast acceleration from the idle run to the range near the maximum and then maximum rpm) may lead to disturbances in flow of air stream. Such a phenomenon is extremely hazardous when flights are performed at low altitudes when each spontaneous flameout of an engine (that is frequently associated with unsteady operation of an engine) is a direct danger to life of the plane craft.

The process of unsteady operation of an aircraft engine can be traced on the diagram of fuel consumption $Q$ as a function of the engine $\mathrm{rpm} n$. When the engine control lever (DSS) is repositioned towards growth of the engine speed, the amount of fuel supplied to the combustion chamber increases as well (the green line in Fig. 8). However, such a curve is not very realistic since it takes place only in the case when the engine control lever is moved very slowly from the rotation speed of idle run to the maximum rpm. In practice, movements of the engine control ever are more or less violent that leads to acceleration or deceleration of the rotating engine shafting. It is why the green line (in particular in the initial phase of accelerations approaches to the boundary of steady operation that is referred to as the stall border (the red line in Fig. 8 and 9) [8].

Structures of turbojet engines sometimes-incorporate units (subassemblies) that are called acceleration automate. The purpose of these devices is to prevent from excessive fast growth of fuel amount that is supplied to the combustion chamber in when movements of the engine control lever are too fast. It makes to slow down excessively rapid growth of the engine rpm that otherwise may lead to intersection of the both lines and occurrence of the engine unsteadiness (Fig. 10). 


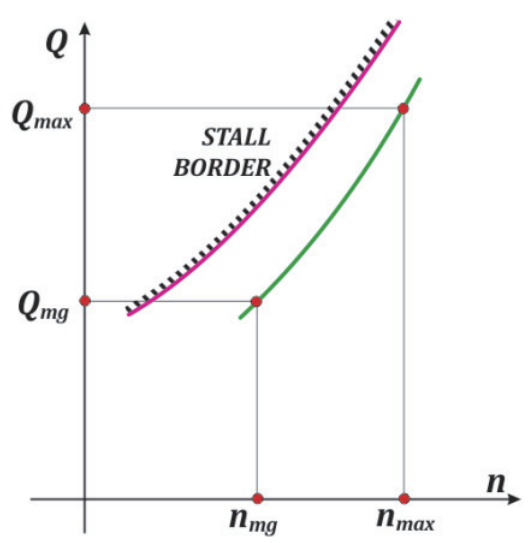

Fig. 7. Nature of fuel consumption $Q$ as a function of the engine rpm $n$ for slow acceleration of the engine rpm

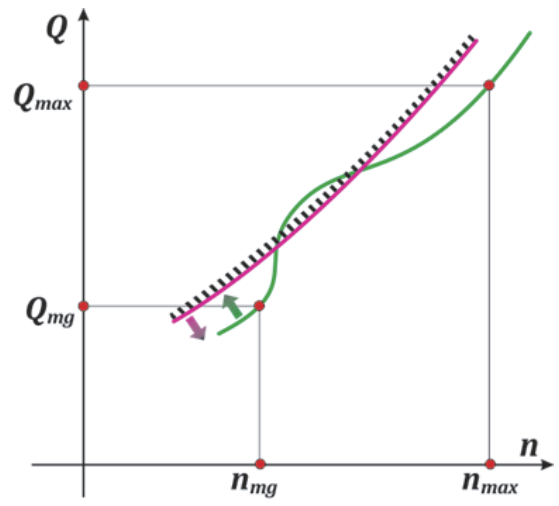

Fig. 9. Intersection of the stall order during the engine acceleration

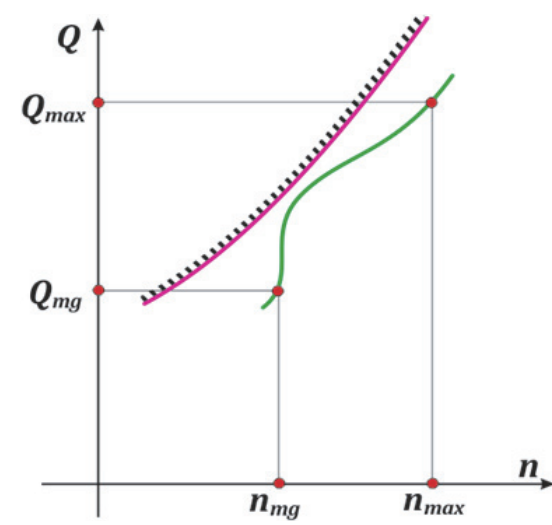

Fig. 8. Approaching of the fuel consumption curve to the stall border during the engine acceleration

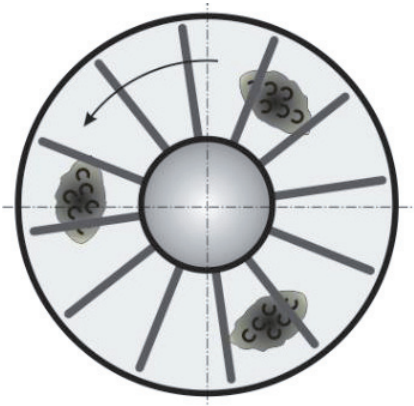

Fig. 10. Rotating areas of detached air stream when the effect of compressor stall takes place

The effect of the engine unsteadiness is associated with so-called areas of detached air stream (Fig. 11) that rotate in pace with the direction of the engine rotor revolutions but with lower speed. Flames behind such areas is put out for a moment (too much fuel with regard to the amount of air) and then reappears due to quite fast supplying of air. If that process is to in the same phase with the rotating areas of detached air stream the effect of engine flameout may take place.

\subsection{Examples of avionic events associated with symptoms of engine unsteadiness}

\subsubsection{Suction of gunpowder gas}

It may happen during operation of combat airplanes or helicopters (armed with missiles) that the intake duct of the aircraft engine gets into the line of exhaust gas ejected by engines of other aircrafts or gunpowder gas from just launched missiles. Such ingresses frequently lead to the effect of engine stall or even to its flameout. It is the phenomenon that may become the direct reason of an avionic event or even an avionic catastrophe. Suction of gunpowder gas from missile engines into a turbojet engine may affect operation of the latter, in particular:

- its compressor that leads to disturbances of the air stream and unbalanced distribution of the air stream velocity field in the compressor inlet and may also be a reason for the compressor stall,

- thermal effect that is manifested by intense and unequal heating of the air stream sucked by the compressor, which leads to increase of air temperature in the intake and leads to drops of the compressor efficiency and engine power,

- chemical effect that is manifested by contamination of air by gunpowder gas that leads to drop of oxygen content in intake air and may lead to the engine flameout. 
The two first factors and the manner of their effect lead to unevenness of the pressure and temperature fields in the air upstream the compressor. It results in reduction of the reserve for steady operation (curve 4 in Fig. 12a) with simultaneous growth of average temperature upstream the compressor. All these effect lead to deterioration of reduced parameters of the engine rpm $n_{z r}$ and efficiency of the air stream. As a consequence, the working point of the compressor characteristic curve moves down the 0-2 line towards the stall border (Fig. 12a).

Changes in composition of the fuel and air mix supplied to the main combustion chamber results in growth of temperature in the area upstream the turbine and in drop of the totalized coefficient of air excess $\alpha$ with consideration to the fact that the amount of gunpowder gas that is generated when solid fuel of the missile is subjected to combustion remains unaltered with variation of the flight elevation and speed $(1 \mathrm{~kg}$ of solid fuel produces about 800 litres of gunpowder gas). On the other hand, airflow rate of a turbojet engine substantially drops down with growth of the flight altitude, the fuel and air mixture supplied to the combustion chamber becomes richer that leads to approaching of the operation range to the border of "rich mix" and entails the flameout effect, which is indicated by an arrow in Fig. 12b.

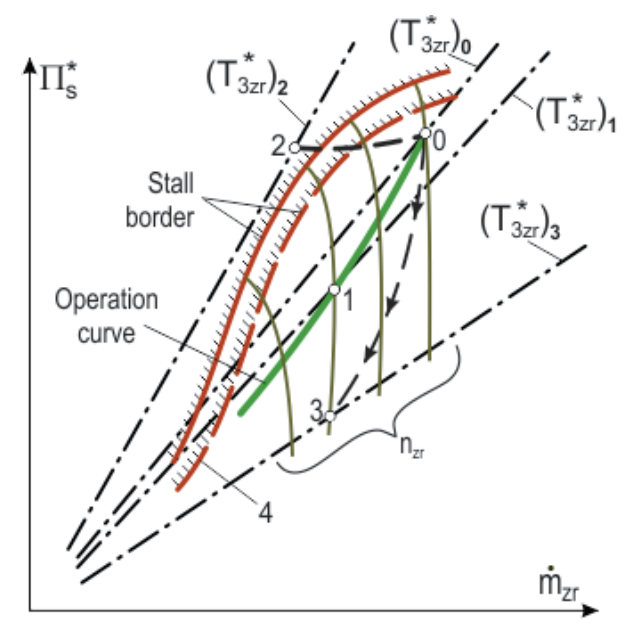

(a)

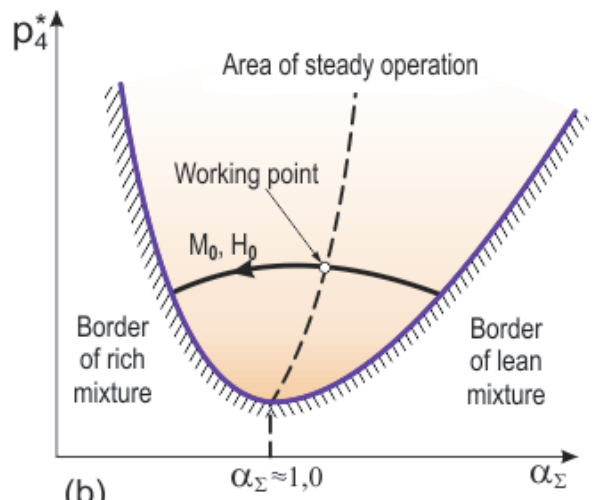

(b)

Fig. 12. Effect of gunpowder gas penetration into the engine intake onto steadiness of the compressor operation (a) and the combustion chamber operation (b) after launching the combat missiles. The zr index stands for parameters reduced to normal conditions [7]

The stall effect that described above took place in the PZL-10W engine that is used to power the W-3W helicopter [50] after launching nine uncontrolled NLPR-70 missiles of the $70 \mathrm{~mm}$ calibre. The reason for the stall effect was penetration of gunpowder gas generated by combustion of solid missile fuel with negative oxygen balance to intake ducts of the PZL-10W turbojet engines. To analyse the mentioned phenomenon it was possible to benefit from information stored in the BUR-1-2 on-board recorder of flight parameters and from images recorded by a video camera.

The "modified" picture (Fig. 13) for a fragment of the waveform for the turbocompressor rpm within the PZL-10W driving unit of the "Sokól" helicopter recorded during the flight when the stall effect of the both engines took place indicates typical symptoms of rpm variation. These include very large and quick jumps of that parameter of the engine operation, which is an adverse effect that entails drop of fatigue strength demonstrated by rotating components of the engine.

Substantial zooming in of the indicated fragment (Fig. 14) makes it possible to infer about the nature and severity of the stall effect. For the case under the analysis the stall proved to be "weak" (insignificant variations of the observed rpm drops). The stall led to drop of rotation speed for the compressor of the right-hand side engine $n_{P}$ (by about 7\%) with nearly intact rpm $n_{L}$ of the turbocompressor for the left-hand side engine. It is also possible to find out that at the moment 
when the low peak (the highest drop) of the right-hand side engine is reached, the left-hand side engine strives to prevent from drop of the lifting propeller rpm $N R$ caused by drop of the righthand side engine rpm, and tends to slightly increasing its rotation speed. It decelerated drop of the lifting propeller rpm and caused subsequent growth of that parameter.

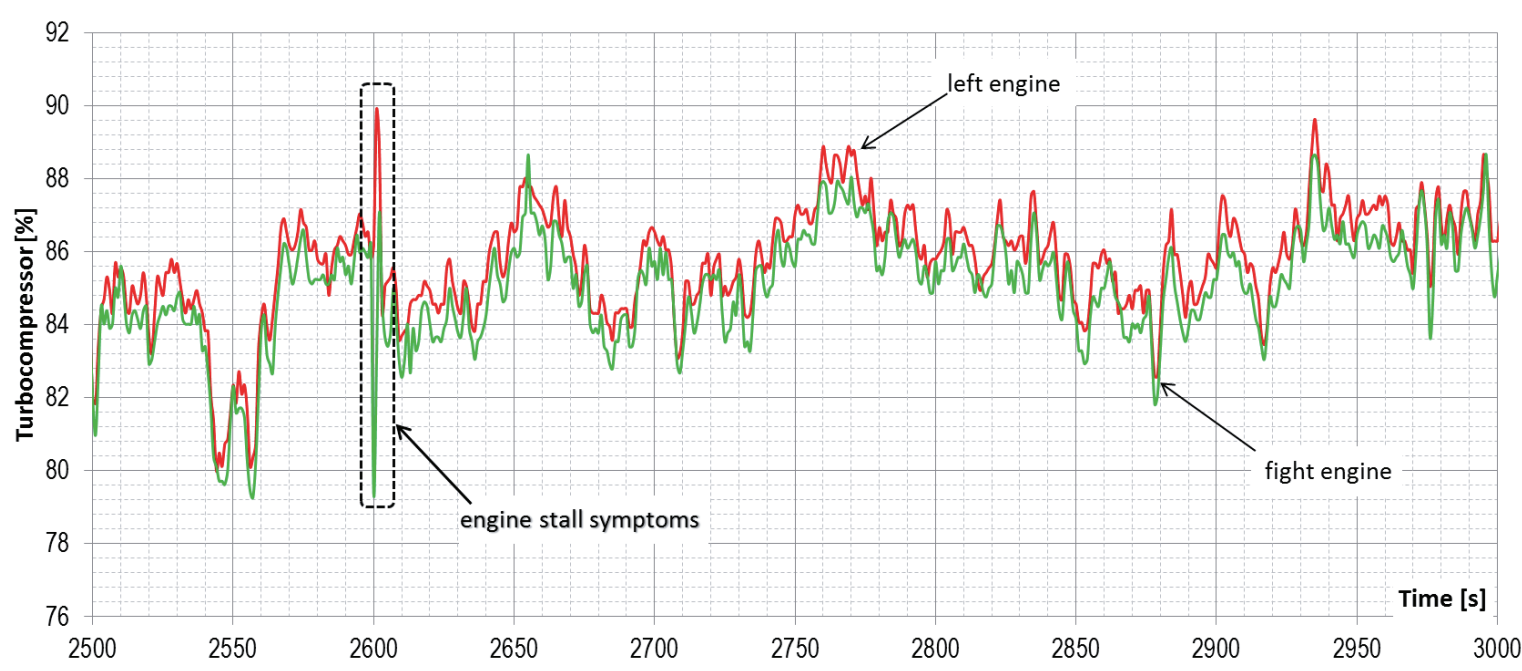

Fig. 13. Nature of rpm variations for left and right engines during the specific flight

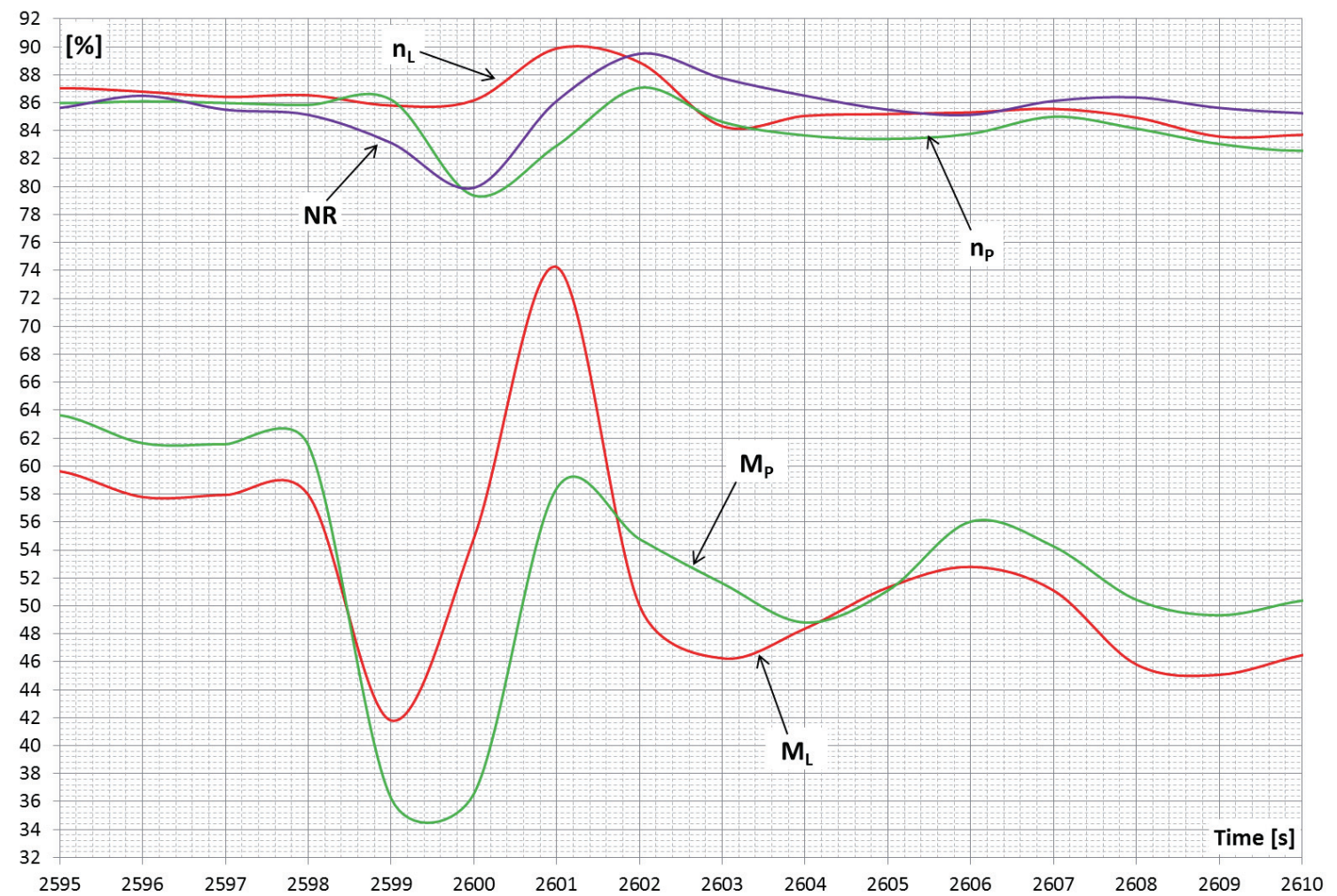

Fig. 14. Nature of variations demonstrated by selected operation parameters of the W-3 driving unit in the "Sokót" helicopter during the stall phenomenon

However, due to the fact that rpm of the right-hand side engine (after a slight time lag) also began to increase the preset (maximum) rotation speed $N R$ of the helicopter rotor (lifting propeller) was exceeded for a short time. Operation of engines was stabilized after termination of the stall effect. Such a behaviour of the driving system is desirable and serves as a proof that the both engines are correctly adjusted. In addition, the analysis of recorded parameters made it possible to 
find out that the violent nature of variations exercised by individual operational parameters of the driving unit due to the stall effect expired after about 3 seconds.

Dynamic properties of variations exercised by individual operation parameters of the aircraft engine during the stall phenomenon caused by intake of gunpowder gas can be also demonstrated by means of other tools, for instance with use of so called phase imaging, i.e. the characteristic curve of the first derivative for the specific parameter as a function of variations exercised by that parameter. Phase imaging also depicts so-called hysteresis of the parameter variations and the area of the hysteresis loop indicates steadiness of a specific parameters in time. The completed investigations made it possible to find out that the variation nature for individual parameters of the engine operation was quite intense and the reaction of the stabilizing feedback loop of the engine control was correct.

\subsubsection{Icing of the intake channel}

Operation of aircraft engines during the autumn and winter period is complicated by changes of weather conditions. Of these, the icing effect is the most dangerous since it deteriorates flying properties of aircrafts, increase their own weight and lead to drop of the engine power and thrust. Therefore the example associated with icing of the intake channel of the TW2-117 turbo-propeller engine is referred to since it shows impact of the icing phenomenon onto the engine operation and its ability to achieve the desired values of basic operational parameters. The most beneficial conditions for occurrence of the icing phenomenon occur that high humidity of air is maintained over a long period with the air temperature above $+5^{\circ} \mathrm{C}$. Icing of intake ducts that supply air to turbine engines leads to distortion of the passing airstreams, which results in resonance vibrations of the compressor blades. In addition, blades can be damaged by detached ice chips. Due to icing of its blades the engine compressor operates unsteadily, that is the result of weight unbalance and changes of aerodynamic forces. In consequence, icing may lead to stall of the engine compressor and then trigger flameout of the driving unit (engine) or even damage of it.

The completed simulation tests with use of the TW2-117 engine have demonstrated that the temperature drop by about 3 to $4^{\circ} \mathrm{C}$ occurs across the distance between the sensor installed upstream the intake duct and the sensor installed upstream the subassembly of adjustable vanes (without inflow of the icing agent) - Fig. 15. Subsequent tests with inducing of the icing phenomenon by supplying of water mist directly to the intake duct have led to the spontaneous flameout of the engine under test. The differential temperature already detected between across the distance between the plane of the intake duct and the plane of the adjustable vanes subassembly was even slightly increased up to 5 to $6^{\circ} \mathrm{C}$ (Fig. 16).

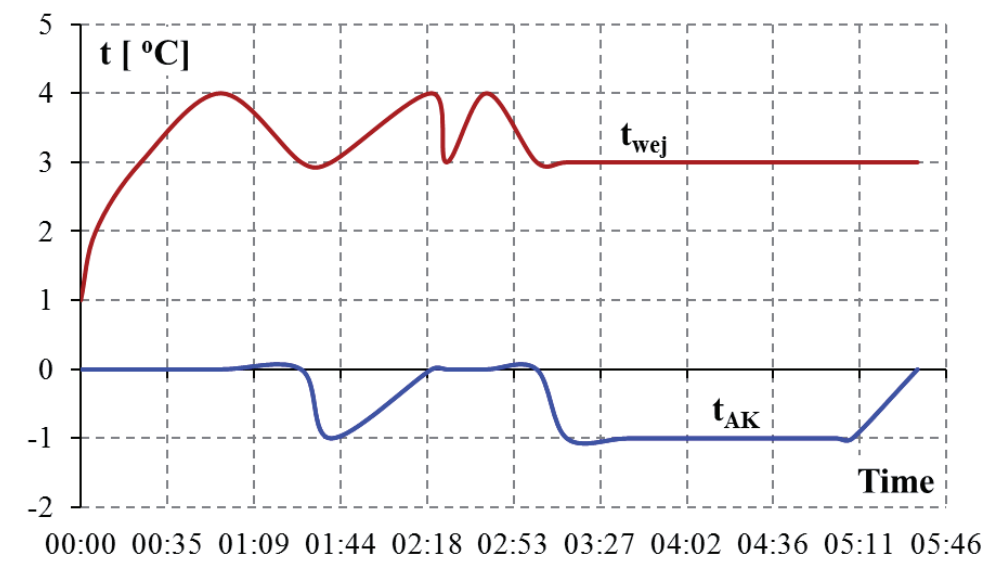

Fig. 15. The absolute differential temperature between the intake duct inlet and the cross-section of the guiding vanes subassembly for the TW2-117 without inflow of the icing agent (the distance of about $40 \mathrm{~cm}$ ) 
Simulation tests demonstrated as well that irregular (random) variations occurred for basic operation parameters of the engine. Subsequent simulation tests associated with supply of water mist at elevated rates $\left(0.5 \mathrm{dm}^{3}\right.$ per minute) with the water temperature of $-3.5^{\circ} \mathrm{C}$ and the freezing ambient temperature $\left(-2^{\circ} \mathrm{C}\right)$ led to four in total, quite vigorous and short stall effects and finally to the engine flameout.

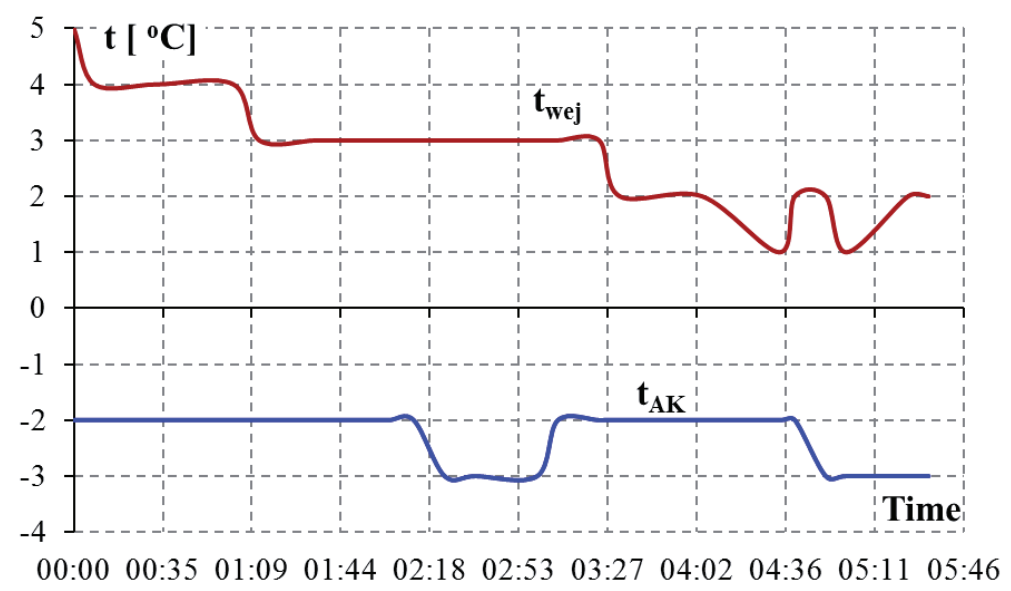

Fig. 16. The absolute differential temperature between the intake duct inlet and the cross-section of the guiding vanes subassembly for the TW2-117 with inflow of the icing agent (the distance of about $40 \mathrm{~cm}$ )

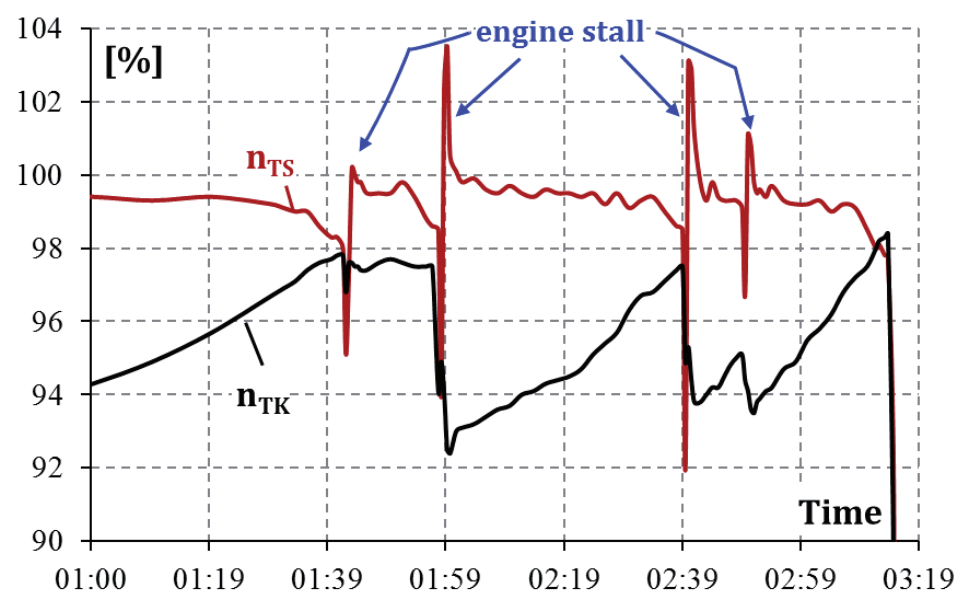

Fig. 17. Rpm variations for the turbocompressor (nTS) and for the driving turbine (nTK)

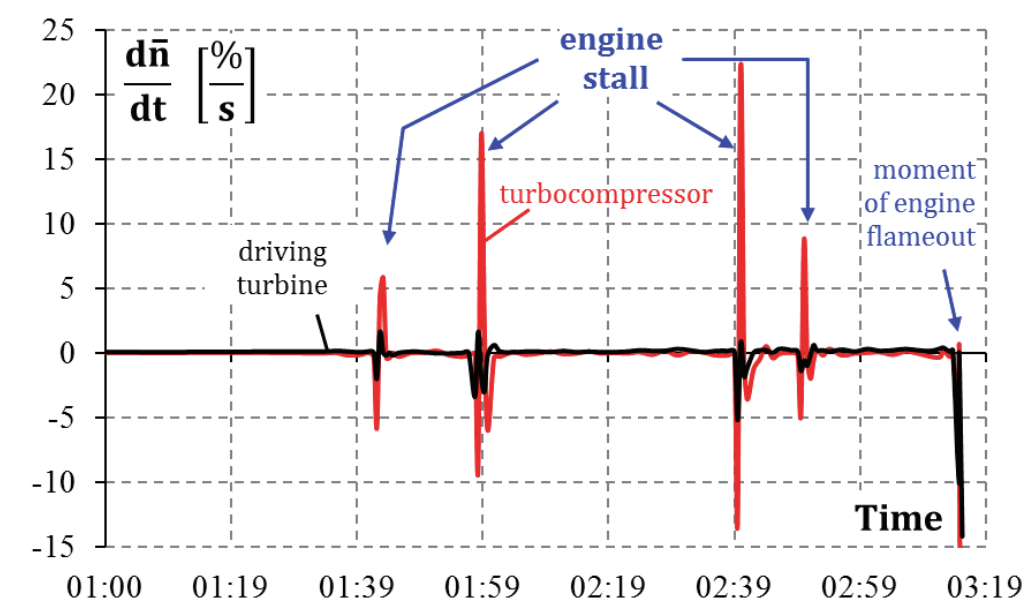

Fig. 18. The derivative for the turbocompressor and driving turbine rotation speeds in time 
The first engine stall took place as early as after $1 \mathrm{~min}$. and $40 \mathrm{sec}$. of the engine operation with the rpm range typical for flight missions. It is highly probably that such a phenomenon, if occurred during a flight mission would end up with rapid flameout of the engine. The total time of the engine operation until its full flameout was $3 \mathrm{~min} .10 \mathrm{sec}$. The sensor of the anti-icing RIO-3 system was triggered after about 10 second after the first engine stall took place. The analysis of variations exercised by the derivatives of the turbocompressor $\mathrm{rpm}\left(n_{T S}\right)$ and the driving turbine rpm $\left(n_{T N}\right)$ makes it possible to find out that disturbances (jumps) of the rotation speed $n_{T N}$ for the driving turbine were the consequences of the compressor stalls. The stall phenomena occurred in the compressor at first and then the aerodynamic coupling with the driving turbine induced disturbances in rotation speed of the driving turbine. One can also find out that drops of the driving turbine rpm are much less (from 3 to 5 times) that corresponding drops of the turbocompressor rpm - Fig. 18.

\section{Conclusions}

Use of information from on-board recorders of flight parameters is definitely justified not only to investigate avionic accidents and catastrophes but also for analysis of insignificant avionic events. In consequence, it is possible to find out the reasons why such phenomena took place and to draw up corresponding preventive measures.

Therefore, it is necessary to install modern recorders of flight parameters or continuously upgrade the existing ones that are currently in operation to enable extended scope of measurement capacities, i.e. improved measurement susceptibility and high quality of recorded parameterized information. It is why further research and development efforts must be continued with regard to the issues associated with avionic events and development of optimized preventive practices. The attention must be focused onto the following issues:

- upgrade of on-board recorders of flight parameters to increase the number or recordable parameters,

- increase of the sampling frequency for the "black boxes" that are currently in use.

It is also indispensable to employ modern numerical methods to improve efficiency of investigations and analyses that are now in progress and anticipated for future.

\section{References}

[1] Cieciura, M., Zacharski, J., Probabilistic methods in practical aspects, Warsaw 2009.

[2] http://www.focus.pl/jak-to-dziala/zobacz/publikacje/czarna-skrzynka/.

[3] Orkisz, M., Impact of the compressor operation control by air bleeding onto the reserve of steady operation, Engineering Transactions, Polish Academy of Sciences, Institute of Fundamental Technical Issues, 1990.

[4] Szczepanik, R., Spychała, J., Kowalski, M., Dzięcioł, E., Pawlak, W., Przysowa, R., Perz, M., Analysis of signals generated by rotor blades of rotary fluid flow machines, ITWL, No. V 2497, Warszawa 2006.

[5] Szczepanik, R., Szczeciński, S., Investigation of conditions for suction of mechanical contaminants into intakes of turbojet engines, Avionic and Astronautic Technologies, Vol. 3, 1978.

[6] Szczepanik, R., Possibilities of stall effect in engines of the "89" series at the moment of missile launching, Technology and Operation, 1980.

[7] Wiatrek, R., Theory of avionic engines, Military University of Technology, Warsaw 1983.

[8] Wirkowski, P., Impact of alterations in positioning of diving vanes in an axial compressor onto operation of a IC turbojet engine; Scientific Journal of Navy, No. 3 (170), 2007. 